\title{
Risk Assessment of Ground Water Inrush from Underlying Aquifers Based on Fuzzy Comprehensive Evaluation and its Application
}

\author{
Bo $\mathrm{Li}^{*}, 1$ and Lei $\mathrm{Xu}^{2}$
}

\author{
${ }^{I}$ Key Laboratory of Karst Environment and Geohazard Prevention, Ministry of Education, Guizhou University, \\ Guiyang, Guizhou, 550007, China \\ ${ }^{2}$ Shcool of Civil Engineering, Hennan Polytechnic University, Jiaozuo, Henan, 454000, China
}

\begin{abstract}
Mining operations in China are often threatened by frequent water inrushes from confined karst aquifers, We need to evaluate the risk from water-inrush from coal floors in order to have safe production in mines. water inrush risk assessment method based on fuzzy comprehensive evaluation is introduced in this paper. A secondary fuzzy comprehensive evaluation system is constructed to evaluate the risk of floor water invasion in coal mines. Four first-grade indices and fifteen second-grade indices are determined based on the principles. The weight of every index is rationally distributed by analytic hierarchy process (AHP). Finally applying the evaluation model based on fuzzy comprehensive evaluation to evaluate floor water disasters of Yuzhou coalmine in Hebei, the evaluation results are accurate. It can provide certain reference and basis for the evaluation of water-inrush from coal floor forecast for the future.
\end{abstract}

Keywords: Analytic hierarchy process, coal floors, fuzzy comprehensive evaluation, water-inrush

\section{INTRODUCTION}

Coal has been one of the main natural resources in China. Safe, efficient, and environmental-friendly mining plays an important role in the nation's economy and social development. However, water disasters in mines have often restricted their production rates. Because of complicated geological and hydrogeological conditions, approximately $27 \%$ of the proved coal reserves are threatened with water hazards. According to the latest statistics from Chinese coal mines in 2008 to 2012 , it is found that coal mine water damage frequently occur, resulting in huge casualties and economic loss (Table 1).

Table 1. Mine water accidents from 2008 to 2012 in China.

\begin{tabular}{|c|c|c|}
\hline Year & Accidents Times & Death Toll \\
\hline \hline 2008 & 49 & 200 \\
\hline 2009 & 21 & 135 \\
\hline 2010 & 18 & 183 \\
\hline 2011 & 13 & 100 \\
\hline 2012 & 7 & 104 \\
\hline
\end{tabular}

In recent years, coal mining developed gradually to the deeper and formed the high stress areas, accompanied with the requirements of mine production and efficiency, mining needs growing exploitation space and increasing mechanization, which obviously increase the chance of ground water inrush during mining underlying aquifers. If not take appropriate control measures promptly, not only water inrush continue to increase, but also the large number of mines threatened by water damage will scrap early. It can be said that the threat from the floor karst high confined water damage has seriously hampered coal mining of China, So the warning and prevention technology of Ground water inrush during mining underlying aquifers should adapt to the new situation. study in-depth on the basic theory of the floor water control and prevention and take more practical innovative research on the prevention method.

The research of water inrush has been popular in recent years with methods varied. Shi et al. evaluated water inrush of coal seam floor by integrating the water inrush coefficient and the information of water abundance [1]; $\mathrm{Hu}$ et al. established a simplified mechanical model to analysis water inrush from the mining floor [2]; $\mathrm{Li}$ et al. used the microseismic monitoring technique to monitor and analyze information carried in the seismic waves generated from either mining-induced rock fracturing or active blasting so as to detect unknown water bodies and reduce water-inrush risk in underground mines [3]; Hua et al. setted up a nonlinear dynamic mathematical model based on the catastrophe theory to predict the risk of water-inrush [4]; $\mathrm{Wu}$ et al. systematically analyzes typical cases about water inrush from coal seam floor in the researched area [5]; Wang et al. constructed the fault tree model of mine water-inrush to assess the risk of water-inrush of Yangzhuang mine [6]; Gao et al. evaluated water inrush from coal floor combined with experts' experiences and artificial intelligence technology [7]; These diverse theories show the complexity of water inrush phenomena. But some of these simplify conditions or factors and fail to profoundly reveal the quantifying relation 
between water inrush and its affecting indices, while others exist some limitations despite their uniqueness to manage the problem of water inrush. The mining and hydrogeological conditions call for new methods to evaluate water inrushes. The method of comprehensive evaluation for risk of floor water inrush proposed based on the theory of fuzzy mathematics fully takes into the main indices affecting water inrush with the advantages from qualitative to quantitative and of high accuracy and universal application.

\section{FUZZY COMPREHENSIVE EVALUATION MODEL}

Fuzzy comprehensive evaluation method is a comprehensive evaluation method based on fuzzy mathematics. Fuzzy comprehensive evaluation method to determine the boundaries are to be completed by the membership function. Maximum membership degree principle is to be applied to grading evaluation objectives. The method fully reflects the impact of the coal floor water bursting factors and the relationship between these factors. General procedure is as follows $[8,9]$ :

Step 1: Evaluation object $U$ by some attributes into $\mathrm{m}$ subsets $\left(\mathrm{u}_{1}, \mathrm{u}_{2}, \ldots . . \mathrm{u}_{\mathrm{m}}\right), \mathrm{m}$ means the number of total subsets, that is to say we evaluate the objects from $\mathrm{m}$ aspects.

Step 2: Making comprehensive evaluation for every subset $\left(\mathrm{u}_{1}, \mathrm{u}_{2}, \ldots \ldots \mathrm{u}_{\mathrm{m}}\right)$, The evaluation set indicated by $\mathrm{V}$ : $\mathrm{V}=\left(\mathrm{v}_{1}, \mathrm{v}_{2}, \ldots \ldots \mathrm{v}_{\mathrm{n}}\right), \mathrm{n}$ means the number of total evaluation sets.

Step 3: Quantify the objects' every factor, that is to determine the object's membership grade of each level fuzzy subsets, and then get the fuzzy relational matrix:

$$
R=\left(\begin{array}{cccc}
r_{11} & r_{12} & \ldots & r_{1 n} \\
r_{21} & r_{22} & \ldots & r_{2 n} \\
\vdots & \vdots & \ddots & \vdots \\
r_{m 1} & r_{m 2} & \ldots & r_{m n}
\end{array}\right)
$$

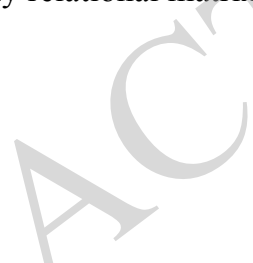

Step 4: Determine the weight vector of every factor to reflect the importance of the factors. The factor weights are determined by analytic hierarchy process in this paper. $a_{i}$ indicate the weight of factor $\mathrm{i}$, and $1 \geq a_{i} \geq 0 ; \sum a_{i}=1$. matrix $A=\left(a_{1} a_{2} \cdots a_{m}\right)$.

Step 5: The fuzzy comprehensive evaluation vector B is obtained by composite matrix $\mathrm{A}$ and the fuzzy relational matrix R with appropriate composition operator:

$$
B=A \circ R=\left(a_{1}, a_{2} \ldots a_{m}\right) \circ\left(\begin{array}{cccc}
r_{11} & r_{12} & \ldots & r_{1 n} \\
r_{21} & r_{22} & \ldots & r_{2 n} \\
\vdots & \vdots & \ddots & \vdots \\
r_{m 1} & r_{m 2} & \ldots & r_{m n}
\end{array}\right)
$$

\section{MAIN FACTORS OF COAL FLOOR WATER BURSTING}

In order to evaluate inrush risk of coal floor water, we must first determine the appropriate evaluation factors.
Mining practice over the years illustrate the factors which influence the evaluation of mine water inrush is multifaceted [10]. According to the feasibility, representativeness and accuracy, this paper chooses four main factors:

\subsection{The Nature of Floor Aquifer}

The nature of floor aquifer is one of the key factors for coal floor water disaster. Water inrush accident will happen only in strong water-rich region, when the water guide passage is formed under the action of water pressure. If in the water-poor region, it will not cause much harm even water guide channel can reach the aquifer. In this paper, water pressure of aquifer, specific yield, coefficient of permeability and aquifer thickness were considered to judge the nature of the aquifer.

\subsection{Geological Structure}

The relationship between geological structure and water damage is very close. The nature of the geological structure will have an impact on the water abundance. Construction would undermine the integrity of the impermeable layer, and some faults and fractures will become a channel of water inrush. So geological structure is an important factor for assessment of ground water inrush, in this paper, structural nature, structure density, development situation of karst collapse column and development situation of fractured were considered to judge the nature of geological structure.

\subsection{Confining Layer}

Confining layer is the key to prevent water inrush from coal floor, and is natural geological protection for preventing water inrush. The ability of confining layer to prevent water inrush is mainly reflected in the aquiclude thickness, mechanical strength and integrity of the aquiclude. Large thickness, well integrity and strong compressive can effectively reduce the height of water which flow through fractured zone. The above three aspects were considered to judge the nature of confining layer.

\subsection{Mining Disturbance}

Along with mining progresses, the floor surrounding rock will form rock pressure damage zone. Rock pressure damage zone is an important incentive for water inrush. Coal seam thickness, mining depth, working face length and coal seam dip were considered to judge the nature of mining disturbance. The larger coal seam thickness, the deeper seam depth, the longer the working length and the steeper seam inclination, the more likely to cause water inrush.

\section{EVALUATION INDICES AND GRADING STANDARDS}

In this paper, the risk assessment of water bursting is divided into four grades, small (I), relatively small (II), relatively large (III), large (IV). After considering China's national standards, industry standards, and results of previous studies, establishing the coal floor water-irruption evaluation index system and grading standards integrating 
Table 2. Grading standard of influencing factors.

\begin{tabular}{|c|c|c|c|c|c|}
\hline \multirow{2}{*}{\multicolumn{2}{|c|}{ Factors }} & \multicolumn{4}{|c|}{ Evaluation Grading Standards } \\
\hline & & I & II & III & IV \\
\hline Floor aquifer & $\begin{array}{l}\text { water pressure of aquifer }(\mathrm{Mpa}) \\
\text { specific yield }(\mathrm{L} /(\mathrm{sm})) \\
\text { Coefficient of Permeability }(\mathrm{cm} / \mathrm{s}) \\
\text { Aquifer thickness }\end{array}$ & $\begin{array}{l}\text { small } \\
0.01 \\
10-6 \\
\text { small }\end{array}$ & $\begin{array}{l}\text { relatively small } \\
\qquad \begin{array}{l}1 \\
10-4 \\
\text { relatively small }\end{array}\end{array}$ & $\begin{array}{c}\text { relatively large } \\
5 \\
10-2 \\
\text { relatively large }\end{array}$ & $\begin{array}{c}\text { large } \\
10 \\
1 \\
\text { large }\end{array}$ \\
\hline Confining layer & $\begin{array}{c}\text { Aquiclude thickness } \\
\text { The compressive strength of the rock (Mpa) } \\
\text { The integrity index of the rock }\end{array}$ & $\begin{array}{l}\text { Large } \\
54.6 \\
0.75\end{array}$ & $\begin{array}{l}\text { relatively large } \\
\qquad \begin{array}{c}29.1 \\
0.55\end{array}\end{array}$ & $\begin{array}{l}\text { relatively small } \\
\begin{array}{c}19.6 \\
0.35\end{array}\end{array}$ & $\begin{array}{c}\text { small } \\
8.5 \\
0.15\end{array}$ \\
\hline Geological structure & $\begin{array}{c}\text { Structural complexity } \\
\text { Fracture density (\%) } \\
\text { development situation of karst collapse column } \\
\text { structure density }\end{array}$ & $\begin{array}{l}\text { Complex } \\
2 \\
\text { Little } \\
\text { small }\end{array}$ & $\begin{array}{l}\text { relatively simple } \\
\qquad 5 \\
\text { relatively little } \\
\text { relatively small }\end{array}$ & $\begin{array}{l}\text { relatively complex } \\
\text { Relatively multi } \\
\text { relatively large }\end{array}$ & $\begin{array}{l}\text { complex } \\
\qquad 10 \\
\text { multi } \\
\text { large }\end{array}$ \\
\hline Mining disturbance & $\begin{array}{l}\text { Coal seam thickness }(\mathrm{m}) \\
\text { mining depth } \\
\text { working face length } \\
\text { coal seam dip }\left(^{\circ}\right)\end{array}$ & $\begin{array}{l}0.5 \\
\text { small } \\
\text { small } \\
5\end{array}$ & $\begin{array}{l}\qquad 1.3 \\
\text { relatively small } \\
\text { relatively small } \\
15\end{array}$ & $\begin{array}{l}3.5 \\
\text { relatively large } \\
\text { relatively large } \\
25\end{array}$ & $\begin{array}{c}8 \\
\text { large } \\
\text { large } \\
45\end{array}$ \\
\hline
\end{tabular}

the quantitative and qualitative indicators, evaluation criteria in Table 2.

\section{DERIVATION OF MEMBERSHIP FUNCTIONS OF INDICES}

\subsection{Quantitative Indexes}

In this paper linear fuzzy number membership function is chosen to get membership functions of quantitative indices. Formula is as follows:

$$
\text { When } \mathrm{j}=1 \text {, }
$$

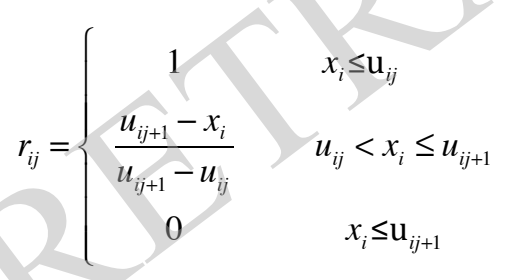

when $1<\mathrm{j}<\mathrm{m}$,

$$
r_{i j}=\left\{\begin{array}{cc}
0 & x_{i} \leq u_{i j-1} \text { or } x_{i} \geq \mathrm{u}_{i j+1} \\
\frac{x_{i}-u_{i j-1}}{u_{i j}-u_{i j-1}} & u_{i j-1}<x_{i} \leq u_{i j} \\
\frac{u_{i j+1}-x_{i}}{u_{i j+1}-u_{i j}} & u_{i j} \leq x_{i} \leq u_{i j+1}
\end{array}\right.
$$

when $\mathrm{j}=\mathrm{m}$,

$$
r_{i j}=\left\{\begin{array}{cc}
0 & x_{i} \leq \mathrm{u}_{i j-1} \\
\frac{x_{i}-u_{i j-1}}{u_{i j}-u_{i j-1}} & u_{i j-1}<x_{i}<u_{i j} \\
1 & x_{i} \geq \mathrm{u}_{i j}
\end{array}\right.
$$

$\mathrm{r}_{\mathrm{ij}}$ - The membership of $\mathrm{i}$ measured values belong $\mathrm{j}$ level; $\mathrm{x}_{\mathrm{i}}$-The measured value of $\mathrm{i}$ evaluation indicators; $\mathrm{u}_{\mathrm{ij}}-\mathrm{j}$ level standard value corresponds to i evaluation indicators.

\subsection{Qualitative Indexes}

The qualitative indexes are divided into four levels, namely I (Very Low), II (Low), III ( High risk), and IV (Very High risk). Corresponding critical value is 1, 2, 3, 4. membership functions of qualitative indexes calculated as follows:

$r_{\mathrm{I}}(x)=\left\{\begin{array}{cc}1 & x<1 \\ 2-x & 1 \leq x<2 \\ 0 & 2 \leq x\end{array}\right.$

$r_{\mathrm{II}}(x)=\left\{\begin{array}{cc}0 & x<1 \\ x-1 & 1 \leq x<2 \\ 3-x & 2 \leq x<3 \\ 0 & 3 \leq x\end{array}\right.$

$r_{\mathrm{III}}(x)=\left\{\begin{array}{cc}0 & x<2 \\ x-2 & 2 \leq x<3 \\ 4-x & 3 \leq x<4 \\ 0 & 4 \leq x\end{array}\right.$ 
$r_{\mathrm{IV}}(x)=\left\{\begin{array}{cc}0 & x<3 \\ x-3 & 3 \leq x<4 \\ 1 & 3 \leq x\end{array}\right.$

\section{ANALYTIC HIERARCHY PROCESS}

The determination of factor index weight in this paper use Analytic Hierarchy Process (AHP), be put forward by operation researcher of USA Saaty in 1980s [11], AHP is a decision making method of practical and multi-program or multi-objective. Its main feature is that it reasonably combines qualitative and quantitative decisions together, making decision process hierarchical and quantitative in accordance with the laws of thinking and psychology. The method is rapidly applied in various fields of the social economy for the advantage of system and flexible and concise as well as the character that process various decision factors by the combination of qualitative and quantitative, such as energy systems analysis, urban planning, economic management, research evaluation etc. both has been noticed and used widely, the detailed steps include [12] :

(1) Make the complex issue hierarchical and form a hierarchical structure composed by the target layer, criteria layer and index layers, in which the index layer elements are affiliated to the one or more elements of criteria layer;

(2) adopt "1-9 scale method" to form a judgment matrix (Table 3);

(3) test the consistence of the judgment matrix;

(4) get the weight of the index layer to the target layer weight by calculating layer by layer.

\section{APPLICATION EXAMPLES}

\subsection{General Situation of Study Area}

In this paper, the evaluation model is applied to evaluate the floor water inrush risk of Yuzhou mining area $6102 \mathrm{~N}$ working face, Yuzhou mining area is located in Hebei Province of China, $6 \mathrm{~km}$ south to Yuzhou town and $200 \mathrm{~km}$ south to Baoding, $130 \mathrm{~km}$ north to Xuanhua and $21 \mathrm{~km}$ west to Guanglin town in Shanxi Province. The mine is geographically convenient to the railways from Shacheng to Yuzhou, from Beijing to Baotoum, and from Beijing to Shacheng (Fig. 1).
The main aquifers in this study area are (1) fractured karst aquifer of Upper Cambrian and Lower Ordovician, (2) fissured bedrock aquifer in the coal measure strata, and (3) overlying unconsolidated porous-medium aquifer. According to the exploration data and field statistics, the karst aquifer of Ordovician is characterized with well-developed fissures, high water yield, and faults and folds. The karst aquifer is confined and is the main water bearing strata which influence the safety of mining in the area.

\subsubsection{The Nature of Face Floor Aquifer}

Below coal is mainly limestone of Ordovician, most of gray limestone and argillaceous limestone. Limestone aquifer thickness is $40 \sim 80 \mathrm{~m}$, water pressure $0.7 \sim 1.1 \mathrm{Mpa}$, permeability coefficient is $3.24 \times 10-6 \mathrm{~cm} / \mathrm{s}$, specific yield is $0.0048-0.008 \mathrm{~L} /(\mathrm{sm})$, karst rate is $11.2 \sim 29.2 \%$.

\subsubsection{The Nature of Confining Layer}

Lithology is mainly mudstone, siltstone and fine sandstone and coal. Rock is relatively integrity and few fissures. The compressive strength of the rock is 2247.7 Mpa, and aquiclude thickness is $4070 \mathrm{~m}$.

\subsubsection{The Nature of Mining Disturbance}

Coal seam thickness is relatively stable in the entire 6102 $\mathrm{N}$ working face. Coal thickness between $3.0 \sim 3.5 \mathrm{~m}$, stratigraphic occurrence is relatively flat, seam dip between 5 $\sim 15^{\circ}$, face length is $150 \mathrm{~m}$, coal mining depth between 360 $\sim 390 \mathrm{~m}$. (4). (4) The nature of geological structure

Geological structure is relatively simple in $6102 \mathrm{~N}$ work face. There are three faults, and all faults are normal faults, fault throw $0 \sim 3 \mathrm{~m}$. Meanwhile fault fracture zone diagenetic consolidation, poor hydraulic conductivity performance, small impact on mining.

\subsection{Index Weights Determined}

According to the AHP method, after set up hier-archical structure model, constructed pairwise matrix, and calculated the consistency ratio. Finally, we get weight results, the results is in the Table 4.

\subsection{Fuzzy Comprehensive Evaluation with Engineering Practice}

Based on the hydrogeological data above, the fuzzy judgment matrices of second-grade indices are established

Table 3. Proportional scale and meaning.

\begin{tabular}{|c|c|}
\hline Scale & Meaning \\
\hline \hline one & The two compared elements has the same importance \\
\hline three & Two elements compares, one is slightly more important than the other \\
\hline five & Two elements compares, one is strongly more important than the other \\
\hline seven & Two elements compares, one is extremely more important than the other \\
\hline nine & \\
\hline The reciprocal of two, four, six, eight & When the difference of the pair things between the both, take the middle value of the adjacent judgments above \\
\hline
\end{tabular}




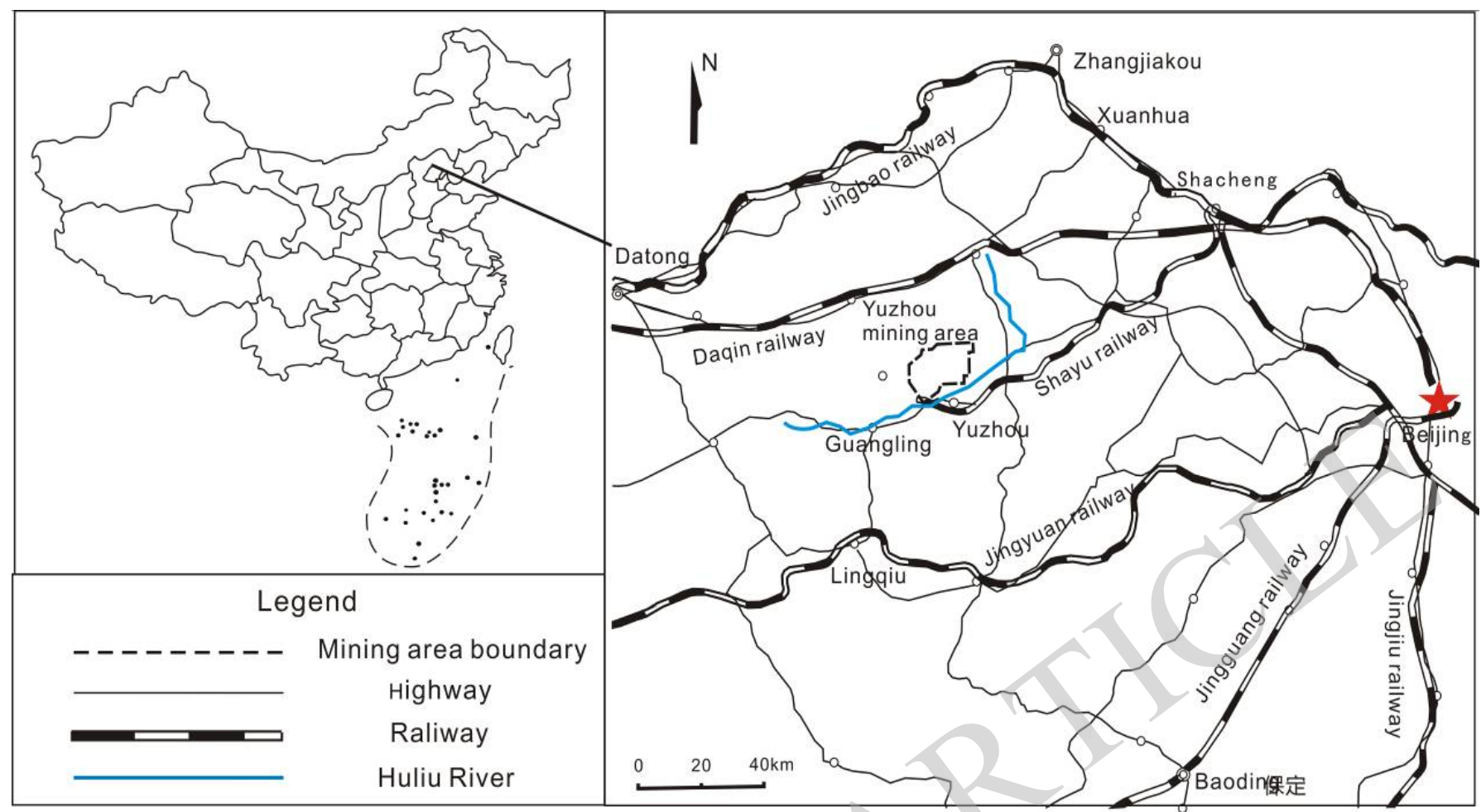

Fig. (1). Site location.

according to the membership of each second-grade index corresponding to risk grade of floor water inrush. Thus fuzzy judgment matrices of second-grade indices are:

$$
\begin{aligned}
\mathrm{R}_{1} & =\left(\begin{array}{cccc}
0.40 & 0.60 & 0.00 & 0.00 \\
1.00 & 0.00 & 0.00 & 0.00 \\
0.977 & 0.023 & 0.00 & 0.00 \\
0.00 & 0.70 & 0.30 & 0.00
\end{array}\right) \\
\mathrm{R}_{2} & =\left(\begin{array}{cccc}
0.6 & 0.4 & 1 & 0 \\
0 & 0 & 0.802 & 0.198 \\
1 & 0 & 0 & 0
\end{array}\right)
\end{aligned}
$$$$
\mathrm{R}_{3}=\left(\begin{array}{cccc}
0.50 & 0.50 & 0.00 & 0.000 \\
0.333 & 0.667 & 0.00 & 0.00 \\
1.00 & 0.00 & 0.00 & 0.00 \\
0.70 & 0.30 & 0.00 & 0.00
\end{array}\right)
$$$$
\mathrm{R}_{4}=\left(\begin{array}{cccc}
0.00 & 0.137 & 0.863 & 0.00 \\
0.00 & 0.00 & 0.80 & 0.20 \\
0.00 & 0.40 & 0.60 & 0.00 \\
0.50 & 0.50 & 0.00 & 0.00
\end{array}\right)
$$

Fuzzy evaluation result $\mathrm{Bi}$ of first-grade indices corresponding to second-grade ones is achieved by choosing appropriate fuzzy operators combined with weight vectors of second-grade index set, taken as membership vector of firstgrade indices one valuation set, and fuzzy judgment matrix is constructed with membership vectors of first-grade indices. Results are obtained as follows:

$\mathrm{B}_{1}=\mathrm{A}_{1} \cdot \mathrm{R}_{1}=\left(\begin{array}{llll}0.597 & 0.339 & 0.064 & 0.000\end{array}\right)$

$\mathrm{B}_{2}=\mathrm{A}_{2} \cdot \mathrm{R}_{2}=\left(\begin{array}{llll}0.396 & 0.604 & 0.000 & 0.000\end{array}\right)$

$\mathrm{B}_{3}=\mathrm{A}_{3} \cdot \mathrm{R}_{3}=\left(\begin{array}{llll}0.667 & 0.333 & 0.000 & 0.000\end{array}\right)$

$\mathrm{B}_{4}=\mathrm{A}_{4} \cdot \mathrm{R}_{4}=\left(\begin{array}{llll}0.097 & 0.225 & 0.620 & 0.058\end{array}\right)$

Thus, the fuzzy judgment matrix of first-grade index is:
$R=\left(\begin{array}{llll}0.597 & 0.339 & 0.064 & 0.000 \\ 0.396 & 0.604 & 0.000 & 0.000 \\ 0.667 & 0.333 & 0.000 & 0.000 \\ 0.097 & 0.225 & 0.620 & 0.058\end{array}\right)$

With weight vector of first-grade indices considered, fuzzy operators of weighted average are chosen to calculate the final evaluation vector as follows:

\section{$\mathrm{B}=\mathrm{A} \cdot \mathrm{R}=\left(\begin{array}{llll}0.366 & 0.232 & 0.278 & 0.124\end{array}\right) \cdot \mathrm{R}$ $=\left(\begin{array}{llll}0.508 & 0.385 & 0.100 & 0.007\end{array}\right)$}

Risk grade of water inrush turns to be very low in $6102 \mathrm{~N}$ working face of Yuzhou mining area according to evaluation result and max- imum membership principle. And the fact that floor water inrush never occurs in actual coalface mining is in accordance with this result.

\section{CONCLUSION}

(1) This paper puts forward a water inrush risk assessment method based on fuzzy comprehensive evaluation. Compared with other water inrush method, our method takes into account various indices and their relationship simply and fast, accurately and practicably, with evaluation results reliable after actual engineering test.

Using the fuzzy comprehensive evaluation method to make comprehensive evaluation, Indicators and the values of weights are very important for accuracy of evaluation results. In actual mining process, not only indices above are considered but also increasing or decreasing indices according to different hydrogeology conditions. Calculation of weights should also be reasonable. 
Table 4. Results of the indicators weight.

\begin{tabular}{|c|c|c|c|c|}
\hline Target Layer & Guidelines Layer & Weights & Index layer & Weights \\
\hline \multirow{4}{*}{ Water inrush risk assessment } & Floor aquifer & 0.366 & $\begin{array}{l}\text { water pressure of aquifer }(\mathrm{Mpa}) \\
\text { specific yield }(\mathrm{L} /(\mathrm{sm})) \\
\text { Coefficient of Permeability }(\mathrm{cm} / \mathrm{s}) \\
\text { Aquifer thickness }\end{array}$ & $\begin{array}{l}0.3123 \\
0.3189 \\
0.1565 \\
0.2123\end{array}$ \\
\hline & Confining layer & 0.232 & $\begin{array}{l}\text { Aquiclude thickness } \\
\text { The compressive strength of the rock (Mpa) } \\
\text { The integrity index of the rock }\end{array}$ & $\begin{array}{l}0.425 \\
0.315 \\
0.26\end{array}$ \\
\hline & Geological structure & 0.278 & $\begin{array}{c}\text { Structural complexity } \\
\text { Fracture density (\%) } \\
\text { development situation of karst collapse column } \\
\text { structure density }\end{array}$ & $\begin{array}{l}0.3135 \\
0.163 \\
0.2987 \\
0.2248\end{array}$ \\
\hline & Mining disturbance & 0.124 & $\begin{array}{l}\text { Coal seam thickness }(\mathrm{m}) \\
\text { mining depth } \\
\text { working face length } \\
\text { coal seam dip }\left(^{\circ}\right)\end{array}$ & $\begin{array}{l}0.2981 \\
0.2905 \\
0.2176 \\
0.1938\end{array}$ \\
\hline
\end{tabular}

\section{CONFLICT OF INTEREST}

The authors confirm that this article content has no conflict of interest.

\section{ACKNOWLEDGEMENTS}

This research was financially supported by Guizhou Province Science and Technology Agency Foundation (qian ke he LH zi [2014] 7617), Guizhou University Introducing Talents Research Foundation (2014-61).

\section{REFERENCES}

[1] L.Q.Shi, M.B Qiu, W.X.Wei, D. Xub, and J. Han, "Water inrush evaluation of coal seam floor by integrating the water inrush coefficient and the information of water abundance", International Journal of Mining Science and Technology, vol.24, pp. 677-681, 2014.

[2] X.Y.Hu, L.G.Wang, Y.L.Lu, and M.Yu, "Analysis of insidious fault activation and water inrush from the mining floor", International Journal of Mining Science and, vol.24, pp. 477-483, 2014.

[3] T. Li, T.T. Mei, X.H. Sun, Y. Lvc, S. Jiquan, and C. Ming, "A study on a water-inrush incident at Laohutai coalmine", International Journal of Rock Mechanics and Mining Sciences, vol. 59, pp. 151-159, April. 2013.

[4] X. Hua, W.Q. Zhang, and D.Z. Jiao. "Assessment Method of waterinrush risk induced by fault activation and Its application research", In Proc. First International Symposium on Mine Safety Science and Engineering, Beijing, pp.441-448, 2011.
J.W.Wu, Z.Q.Jiang, and X.R.Zhai. "Reseach on controlling of rock mass structure on water inrush from coal seam floor in Huaibei mining Area", In: Proc. First International Symposium on Mine Safety Science and Engineering, Beijing, pp. 343 - 350, 2011.

[6] C.S. Wang, Y.J. Sun, and Y. Hang, "Application of fault tree analysis to risk assessment of potential water-inrush hazards in coal mining", Chinese Journal of Rock Mechanics and Engineering, vol. 28, pp 298-305, 2009.

[7] Y. Gao, Y. Zhang, H. Zhang, and S. Wang, "Research on expert system for risk assessment of water inrush from coal floor and its application", Chinese Journal of Rock Mechanics and Engineering, vol.28, pp 253-258, 2009.

[8] J. G. Zhou, Y. X. Wang, and B. Li. "Study on Optimization of Denitration Technology Based on Gray-fuzzy Combined Comprehensive Evaluation Model", In: Proc.The $2^{\text {nd }}$ International Conference on Complexity Science \& Information Engineering, Beijing, pp.210-218, 2012.

[9] L. Zhang, J. N. Pan, and X. M. Zhang, "Fuzzy comprehensive evaluation of mining geological condition in the No.9 coal seam, Linhuan coal mine, Huaibei Coalfield, China", In: Proc. 2011 International Conference on Environmental Science and Engineering, Dalian, pp.240-248, 2012.

[10] Q.Wu. "A new practical methodology of coal seam floor water burst evaluation: The comparison study among ANN, the weight of evidence and the logistic regression vulnerable index method based on GIS ", Meitan Xuebao/Journal of the China Coal, vol.38, pp 2126, 2013.

[11] T.L. Saaty, "The Analytic Hierarchy Process," New York:McGraw-Hill Company, 1980.

[12] G.Y.Lu, Z.Q.Zhu, H.Li, Y. Xiong, and X. Han, "Rock mass classification method in highway tunnel based on fuzzy analytic hierarchy. process", Zhongnan Daxue Xuebao, vol.39, pp.368-374, 2008. 